\title{
Needle-Stick, Sharp Injuries, and Its Related Factors among Nurses of Imam Reza Hospital, Kermanshah, Iran
}

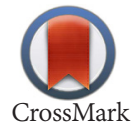

Edris Abdifard ${ }^{1,2}$, Elham Sepahvand ${ }^{3}$, Abbas Aghaei ${ }^{4}$, Saman Hosseini $^{1,2}$, Alice Khachian ${ }^{5 *}$

1. Students Research Committee, Kermanshah University of Medical Sciences, Kermanshah, Iran.

2. Department of Nursing, School of Nursing and Midwifery, Iran University of Medical Sciences, Tehran, Iran.

3. Department of Nursing, University of Social Welfare and Rehabilitation Sciences, Tehran, Iran.

4. Department of Statistics and Epidemiology, School of Health, Shahid Beheshti University of Medical Sciences, Tehran, Iran.

5. Department of Medical Surgical Nursing, School of Nursing and Midwifery, Iran University of Medical Sciences, Tehran, Iran.

cltation: Abdifard, E, Sepahvand, E, Aghaei, A, Hosseini, S \& Khachian, A 2016, 'Needle-stick, sharp injuries, and Its related factors among nurses of Imam Reza hospital, Kermanshah, Iran', Journal of Client-Centered Nursing Care, vol. 1, no. 4, pp. $183-188$.

: http://dx.doi.org/10.15412/J.JCCNC.04010403

Article info:

Received: 17 Apr. 2015

Accepted: 30 Aug. 2015
Keywords:

Needle stick, Sharps injuries, Nurses, Iran

\begin{abstract}
A B S T R A C T
Background: Nurses are at risk of injuries caused by sharp instruments in hospitals. The objective of this study was to investigate the frequency of injuries due to sharp instruments and its relevant factors among nurses of Imam Reza Hospital, Kermanshah, Iran.

Methods: This descriptive-analytic study was conducted on 258 nurses working at Imam Reza Hospital of Kermanshah, Iran, in 2013. The data collection measure was a researcher-made questionnaire, which its validity and reliability were verified. The obtained data were entered into SPSS, version 16 and were analyzed using the Chi-squared and ANOVA test at the significance level of $\mathrm{P}<0.05$.

Results: According to the findings, $73.3 \%(\mathrm{n}=191)$ of nurses were exposed to sharp injuries at workplace. About $41.8 \%$ of cases occurred during the first year of nursing. Major injuries were caused by needle-sticks (73.3\%) and then IV catheter (42.4\%). About $43.5 \%$ of the observed injuries occurred while trying to recap the needle-sticks. Also, $38.52 \%$ of injured nurses performed the tests after injury screening, while $48.7 \%$ did nothing after being injured.

Conclusion: With regard to the findings of this study, human and environmental factors are effective on these exposures and environmental factors are much effective than human factors. It seems necessary to train the personnel, observe general precautions, and change wrong behaviors namely needle re-capping.
\end{abstract}

\section{Background}

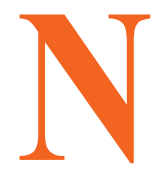

urses, physicians, and other healthcare workers are highly exposed to needle-stick and sharp injuries. Such injuries transfer some pathogens such as (human immuno- deficiency virus) HIV, Hepatitis B virus (HBV), and Hepatitis $\mathrm{C}$ virus (HCV) (Meyer, Chuard \& Regamey 2005; Moro et al. 2007; Martins et al. 2012). Approximately, 66000 cases of HBV, 1600 cases of HCV, and 1000 cases of HIV might occur worldwide among healthcare work-

* Corresponding Author:

Alice Khachian, PhD

Address: Department of Medical Surgical Nursing, School of Nursing and Midwifery, Iran University of Medical Sciences, Rashid Yasemi St., Valiasr St., Tehran, Iran. Tel: +98 (21) 4561607

E-mail: khachian.a@iums.ac.ir 
ers through their exposure to needle-sticks (Moro et al. 2007).

HBV is stable in dried blood for at least 7 days and $\mathrm{HCV}$ for at least 16 months. Thus, such pathogens can be transferred by sharp injuries (Costigliola et al. 2012). The results of some epidemiological studies show that sharp injuries contamination is prevalent in developing countries. About 600-800 thousands cases of needlestick injuries occurred among healthcare workers (Siddique et al. 2008; Gholami et al. 2010). It is estimated that infectious diseases due to sharp injuries cost about \$ 1 million per person but the cost of preventing injuries is about $\$ 3000$ per person (Dement et al. 2004).

Despite much emphasis on the prevention of sharp injuries at work, they are among the potential risks for healthcare workers (Nagao et al. 2007). Annually, 100000 healthcare workers are exposed to contaminated arterial catheters (Moro et al. 2007). All healthcare workers, including physicians, dentists, nurses, lab technicians are exposed to sharp injuries (Alamgir et al. 2008). Among all medical workers in hospitals, nurses are more exposed to HIV, HBV, and HCV due to frequent injections and direct contact with fluids of patients. According to the studies in Europe regarding sharp injuries among healthcare workers, the majority of nurses (91\%) are at risk (Ayranci \& Kosgeroglu 2004).

Numerous patients, shortage of nursing staffs, and heavy workload are the causes that increase the sharp injury contamination risk among nurses (Perry, Parker \& Jagger 2005). Haddadi, Afhami and Karbakhsh (2007) showed that $43.4 \%$ of staffs were exposed to HIV, HBV, and HCV one year before the study and nurses were in the majority group (Haddadi, Afhami \& Karbakhsh 2007). Bijani, Sotudeh Manesh and Mohammadi (2011) reported that in one year, of 172 nurses working in Boalisina Hospital, 55 nurses were exposed to sharp injuries. The activities most related to sharp injuries include injection, medication, venipuncture, and contact with the fluid of patient (Martins et al. 2012).

Improvement of work condition can reduce the increasing risk of sharp injury among nurses (Clarkes, Sloane \& Aiken 2002). In addition, some measurements such as at-service training, work safety, lower work shifts, and no injection during fatigue of staff can reduce sharp injury contamination in hospitals (Trim et al. 2003; AzarCavanagh, Burdt \& Green-McKenzie 2007; Smith et al. 2006a). As B hepatitis vaccination is the only way to prevent sharp injuries contamination, vaccination of medical group, especially nurses is of great importance
(Bijani, Sotudeh Manesh \& Mohammadi 2011). In the study done by Mohammad Nejad et al. (2009) in Imam Khomeini Hospital in Tehran (2009), sharp injuries was $47.05 \%, 82.4 \%$ of nurses vaccinated against hepatitis. After sharp injury, $96.9 \%$ of nurses washed their hands and $12.5 \%$ took drug against HIV.

Hospital accidents are of great importance due to their great life, financial, and social damages. The first step to improve preventive measurements is recognition of effective factors on their occurrence. As the sharp injury risk is common among nurses, determining frequency and the causes of sharp injuries can lead to taking measures to reduce contamination risk. The objective of the study was to determine the frequency of sharp injuries and relevant factors among nurses in Imam Reza Hospital in Kermanshah, Iran, in 2012 and evaluate their performance during these injuries.

\section{Materials \& Methods}

The study method was a descriptive-analytic and cross sectional design. It was conducted in Imam Reza Hospital affiliated to University of Kermanshah Medical Sciences, Kermanshah, Iran, in 2012. The researchers referred to all clinical units of Imam Reza Hospital as the greatest health educational center in the west of Iran. A total of 258 nurses were chosen as study sample. For data collection, a researcher-made questionnaire in 3 parts was designed. The first part consisted of 9 items on demographic data, the second part with 15 items on exposure to sharp injury, and the third part with 7 items about risky factors. The questionnaire validity was verified by content validity through the evaluation of texts and approval of experts. Its reliability was $76.8 \%$ by test-retest method after completing the questionnaires by 16 nurses.

In this study, some personal questions were asked, so some subjects may not respond to some questions. To solve this problem, the subjects were offered required explanations and assured that the information was confidential and there was no abuse of their responses. The inclusion criteria were working in Imam Reza Hospital during the study. The exclusion criteria comprised not responding the questions or delivering incomplete questionnaires. The data entered into SPSS, version 16 and were analyzed using the Chi-square and ANOVA test at the significance level of $\mathrm{P}<0.05$.

\section{Results}

The results showed that of 258 participants, 203(78.4\%) were females and 56(21.6\%) were males. The mean(SD) 
Table 1. Relationship between demographic variables and needle-stick or other sharp injuries among nurses.

\begin{tabular}{|c|c|c|c|c|c|}
\hline \multicolumn{2}{|c|}{ Effective factors on injuries } & $\begin{array}{c}\text { Injured } \\
n(\%) \text { or } M(S D)\end{array}$ & $\begin{array}{c}\text { Non-injured } \\
n(\%) \text { or M (SD) }\end{array}$ & Total & P-value \\
\hline \multicolumn{2}{|r|}{ Age } & $32.42(6.09)$ & $32.31(6.07)$ & $31.99 \pm 6.05$ & 0.614 \\
\hline \multirow{2}{*}{ Gender } & Female & $156(76.8)$ & $47(23.2)$ & $203(100)$ & \multirow{2}{*}{0.025} \\
\hline & Male & $35(62.5)$ & $21(37.5)$ & $5(100)$ & \\
\hline \multirow{2}{*}{$\begin{array}{l}\text { Marital } \\
\text { status }\end{array}$} & Single & $80(74.8)$ & $27(25.2)$ & 107(100) & \multirow{2}{*}{0.434} \\
\hline & Married & $111(73)$ & $41(27)$ & $152(100)$ & \\
\hline \multirow{3}{*}{ Degree } & Associate & $0(0)$ & $2(100)$ & $2(100)$ & \multirow{3}{*}{0.057} \\
\hline & BSc & $181(75.5)$ & $62(25.5)$ & $243(100)$ & \\
\hline & MSc & $10(71.4)$ & $4(28.6)$ & $14(100)$ & \\
\hline \multirow{4}{*}{$\begin{array}{c}\text { Work place } \\
\text { ward }\end{array}$} & Interal & $57(73.1)$ & $21(26.9)$ & $78(100)$ & \multirow{4}{*}{0.141} \\
\hline & Surgery & $47(85.5)$ & $8(14.5)$ & $55(100)$ & \\
\hline & ICU & $60(68.2)$ & 28(31.8) & $88(100)$ & \\
\hline & Emergency and operation & $27(71.1)$ & $11(28.9)$ & $38(100)$ & \\
\hline \multirow{3}{*}{ Position } & Head nurse & $9(69.2)$ & $4(30.8)$ & $13(100)$ & \multirow{3}{*}{0.103} \\
\hline & Staff nurse & $7(50)$ & $7(50)$ & $14(100)$ & \\
\hline & Nurse & $175(75.4)$ & $57(24.6)$ & $232(100)$ & \\
\hline \multicolumn{2}{|c|}{ Clinical experience } & $8.41(6.09)$ & $32.42(6.49)$ & $32.42(6.09)$ & 0.874 \\
\hline
\end{tabular}

Table 2. Relative and absolute frequency distribution of samples based on the causes of not reporting injury to supervisor or infection control expert.

\begin{tabular}{|c|c|c|}
\hline Statistical index Causes of not reporting injury & \multicolumn{2}{|c|}{ F } \\
\cline { 2 - 3 } & $\mathbf{n}$ & 7.5 \\
\hline I was not aware of reporting method. & 6 & 10 \\
\hline I didn't know to whom I report? & 8 & 10 \\
\hline I was not aware of the significance of reporting. & 8 & 26.3 \\
\hline I was not sure about the injury significance. & 21 & 31.3 \\
\hline I had no time to follow the injury. & 25 & 38.8 \\
\hline I didn't think, serious risk exists. & 31 & 11.3 \\
\hline There was no person or place to report. & 9 & 21.3 \\
\hline Reporting was useless. & 17 & \\
\hline
\end{tabular}

Table 3. Relative and absolute frequency distribution of subjects in terms of injury factor.

\begin{tabular}{|c|c|c|c|}
\hline \multirow[t]{2}{*}{ Statistical index } & \multirow[b]{2}{*}{ Injury factor } & \multicolumn{2}{|c|}{$\mathbf{F}$} \\
\hline & & $\mathbf{n}$ & $\%$ \\
\hline Needle-stick & & 140 & 73.3 \\
\hline Angiocatheter & & 81 & 42.4 \\
\hline Blade & & 9 & 4.7 \\
\hline Stitch needle & & 15 & 7.9 \\
\hline Others & & 5 & 2.6 \\
\hline
\end{tabular}




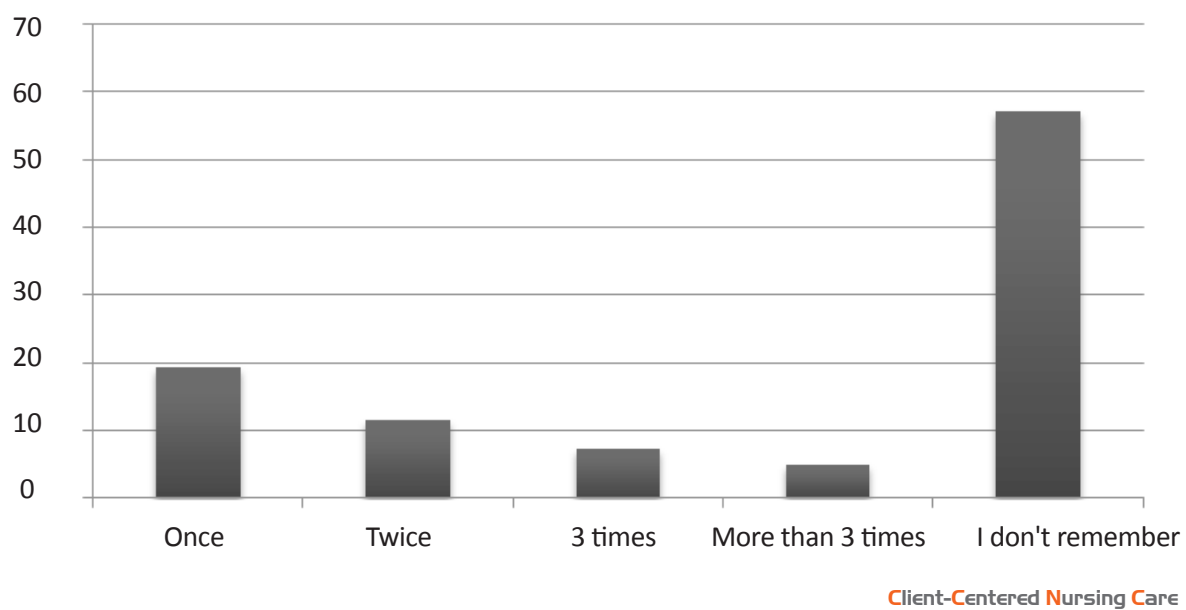

Figure 1. Relative frequency distribution of subjects in terms of frequency of sharp injuries in the past year of study.

age of participants was 32.31, their mean(SD) clinical work experience was $8.45(5.79)$ years, and mean(SD) extra work was $82.47(48.42)$ hours in month. The majority of subjects were married (58.7\%), had BA degree $(93.8 \%)$, working in ICU $(34 \%)$, with rotational shift (78.4\%) (Table 1).

The majority of subjects (73.3\%) were exposed to sharp injuries at work place. About $64 \%(n=166)$ of injuries occurred in the recent year, of which $19.3 \%$ experienced at least one exposure to sharp injuries at work place in the last year (Figure 1). The results showed that $62.2 \%$ of samples mentioned their first action after sharp injuries as "pressing the wound site". About half of the subjects (48.7\%) did nothing after sharp injuries at work place.

Regarding the relationship between demographic factors and injuries, there was only a significant association between the sharp injuries and gender $(\mathrm{P}=0.025)$ and the number of injuries was higher among female nurses. In this study, it was shown that $43 \%$ of subjects did not report the sharp injuries to the supervisor or infection control staff. They stated the major cause of no report as "I didn't think I was seriously in danger" (38.8\%) (Table 2). In this study, nurses stated the major causes of injuries as needlestick (73.3\%) and then angiocatheter (42.4\%) (Table 3).

\section{Discussion}

The results of the present study showed that frequency of needle-stick and sharp injuries was 73.3\%(n=191) among nurses of Imam Reza Hospital. Of which, 64\%(n=166) occurred in the recent year. Frequency of these injuries was reported different in similar studies in Iran and other countries. In the study of Mohammad Nejad et al. (2009) on nurses of Imam Khomeini Hospital in Tehran, $47.5 \%(n=32)$ of nurses were exposed to sharp injuries during their activities. In the study of Nasiri et al. (2005), $76.7 \%$ of healthcare workers were exposed to sharp injuries in the past year. In the study of Bijani, Sotudeh Manesh and Mohammadi (2011) on 172 nurses in Boalishina Hospital of Qazvin, the results showed that $32 \%(n=55)$ of them were exposed to sharp injuries in the past one year. In the study of Ayranci and Kosgeroglu (2004), 62.9\% of nurses had reported sharp injuries at least once. According to a study by Park et al. (2008), nurses had experienced most of the injuries after physicians.

Nurses are exposed mostly to sharp injuries due to spending much time with patients, injection and invasive intervention for patients. In addition, extra work and frequent shifts can increase injury and based on complications of these injuries, training should be given to nurses to reduce these damages.

The present study showed that the mean(SD) age of the nurses was $32.31(6.07)$ years and $42.1 \%$ of them had clinical experience of 5-9 years. Also, the mean(SD) clinical experience of the subjects was 8.45(5.79) years. In similar studies, sharp injuries were prevalent among young and low experienced forces (Haddadi, Afhami \& Karbakhsh 2007; Bijani, Sotudeh Manesh \& Mohammadi 2011). Presumably, giving clinical responsibilities to young staff and managerial positions to experienced personnel (and with fewer contacts with patients) are the causes of high prevalence of sharp injuries among young forces. This study showed that sharp injuries were higher among female nurses $(\mathrm{P}=0.025)$. In other studies, there 
was no significant association between injury and gender (Haddadi, Afhami \& Karbakhsh 2007; Smith et al. 2006b; Bijani, Sotudeh Manesh \& Mohammadi 2011). The causes of injuries in female forces are due to their lower physical ability, fatigue, anxiety, stress of work, and loss of concentration.

About $62.2 \%$ of subjects mentioned their first action after sharp injuries at work place as "pressing the wound site". About half of the subjects (48.7\%) performed no action after sharp injuries. The results of studies showed that pressing wound site to take out blood had no effect on infection (Koohestani, Baghcheghi \& Rezayee et al. 2010). Thus, other methods as washing hands and prophylaxis treatments should be done to reduce contamination.

The present study showed that more than half of the subjects $(57 \%)$ reported the injury to a supervisor or infection control staff and this was consistent with the results of Bijani, Sotudeh Manesh and Mohammadi (2011) study in Qazvin (60\%). In the studies of Smith et al. (2006b) and Martins et al. (2012), a few staffs did not report sharp injuries because of unawareness, insignificance of injury cases, or the fear of being accused of having no clinical skill. In our study, many staffs reported injury cases due to the high cause of informing authorities, holding at-service training, and preventive or prophylaxis treatments.

In this study, the most important causes of not reporting were lack of risk perception (38.8\%), no time for follow up $(31.3 \%)$, not sure of injury significance $(26.3 \%)$, and useless reporting $(21.3 \%)$. In the studies done by Mohammad Nejad et al. (2009) and Azadi and Anoosheh (2007), the most important causes of lack of report were dissatisfaction with follow up, lack of knowledge of reporting process, lack of risk perception, and much work. This problem can be solved by training healthcare workers regarding correct reporting process and explanation of special importance of diagnosis and treatment.

In the present study, most of the injuries occurred during venipuncture (45\%) and needle recapping (43.5\%). The highest injury was due to needle stick $(73.3 \%)$ and then angiocatheter (42.4\%). These findings are consistent with the results of similar studies. In the study of Gholami et al. (2010), the major injuries was due to needle-stick (47.3\%) and angiocatheter (19.9\%). In the study of Vahedi et al. (2006), needle-stick created 43.7\% and angiocatheter $35.3 \%$ of injuries. According to the study of Mohammad Nejad et al. (2009), the most common cause of injury was needle recapping (46.9\%).
As nurses have much work in hospitals such as serum administration, antibiotic therapy, and intravenous treatments; This group is highly exposed to needle-stick injury. Also, high work load and resulting fatigue in work shifts can increase risk of injuries. In this study, only $38.2 \%$ of injured nurses performed the appropriate tests such as HBS Ag, HIV Ab, and HCV Ab, also 12.6\% mentioned counselling with physicians, $8.9 \%$ received $\mathrm{B}$ hepatitis vaccination, $1.8 \%$ hyperimmunoglobulin, and $1 \%$ anti-HIV medication. Finally, about $48.7 \%$ did not perform any action.

The results showed that performance of majority of the nurses was not suitable regarding the first action after needle-stick injury. The first step was washing the hands with soap and water and normal saline in cases of mucosal contact with the patients. The studies show that pressing wound for bleeding does not decrease disease transmission risk and it also contaminates the environment (Sepkowitz 2000). Unfortunately, the results of study showed that in $47.8 \%$ of needle-stick injuries, nurses failed to do any action such as washing the wound site and following up sending tests to the patient. The educational and learning strategies should be changed in this regard. Raising awareness about the risk of needle-stick injury and contact with mucous can reduce the number of injuries and increase reporting cases.

In conclusion, the results of the present study showed that different factors were involved in sharp injuries and the most important factors included high work load, hastening, carelessness with needle-stick and sharp objects, as well as crowded environment. Thus, different human and environmental factors are implicated in these injuries and the share of environmental factors is higher. The prevention of this health risk should be on priority for authorities.

\section{Conflict of Interests}

The authors declared no conflict of interests.

\section{Acknowledgements}

The present study was approved (design No. 91051) by the Student Research Committee of Kermanshah University of Medical Sciences. The researchers are grateful to the deputy of research and technology of Kermanshah University. Also, we are grateful to authorities of Imam Reza Hospital and counselling services of research development of Imam Khomeini Hospital of Kermanshah, as well as all nursing staffs of Imam Reza Hospital. 


\section{References}

Alamgir, H, Cvitkovich, Y, Astrakianakis, G, Yu, S \& Yassi, A 2008, 'Needle-stick and other potential blood and body fluid exposures among health care workers in British Columbia, Canada', American Journal of Infection Control, vol. 36, no. 1, pp. 12-21.

Ayranci, U \& Kosgeroglu, N 2004, 'Needle-stick and sharps injuries among nurses in the healthcare sector in a city of western Turkey', Journal of Hospital Infection, vol. 58, no. 3, pp. 216-23.

Azadi, A \& Anoosheh, M 2007, '[Needle-stick injuries reporting among clinical nurses (Persian)]', Iranian Journal of Nursing, vol. 49, no. 20, pp. 7-14

Azar-Cavanagh, M, Burdt, P \& Green-McKenzie, J 2007, 'Effect of the Introduction of An Engineered Sharps Injury Prevention Device on the Percutaneous Injury Rate in Health Care Workers', Infection Control \& Hospital Epidemiology, vol. 28, no 2, pp. $165-70$

Bijani, B, Sotudeh Manesh, S \& Mohammadi, N 2011, '[Epidemiological Features of Needle stick Injuries among nursing staff (Persian)]', Journal of Guilan University of Medical Sciences, vol. 20, no. 77, pp. 67-68.

Clarkes, SP, Sloane, DM \& Aiken, LH 2002, ‘Effects of Hospital Staffing and Organizational Climate on Needle-stick Injuries to Nurses', American Journal of Public Health, vol. 92, no. 7, pp. 1115-9.

Costigliola, V, Frid, A, Letondeur, C \& Strauss, K 2012, ‘Needlestick injuries in European nurses in diabetes', Diabetes $\mathcal{E} M$ tabolism, vol. 38, no. 1, pp. 9-14.

Dement, JM, Epling, C, Ostbye, T, Pompeii, LA \& Hunt, DL 2004, 'Blood and body fluid exposure risks among health care workers: Results from the Duke Health and Safety Surveillance System', American Journal of Industrial Medicine, vol. 46, no. $6,637-48$

Gholami, A, Salarilak, SH, Alinia, T \& Nejad Rahim, R 2010, '[Study of Needle stick injuries among health care workers at teaching hospitals in Urmia (Persian)]', Iranian Journal of Epidemiology, vol. 6, no. 3, pp. 57-61.

Haddadi, A, Afhami, SH \& Karbakhsh, M 2007, '[Evaluation of Epidemiologic Aspects of Occupational Exposures to Hepatitis B, C and HIV in Health Care Workers and the Effective Factors (Persian)]', Journal of TUMS Medical School, vol. 9, no. 65, pp. 59-66.

Koohestani, HR, Baghcheghi, N \& Rezayee, K 2010, ' [Blood contaminated needle stick/sharp objects injuries and exposure to patients' body fluids in medical emergencies Students (Persian)]', Iranian Journal of Critical Care Nursing, vol. 3, no. 2, pp. $5-6$

Martins, A, Coelho, AC, Vieira, M, Matos, M \& Pinto, ML 2012 'Age and years in practice as factors associated with needle stick and sharps injuries among health care workers in a Portuguese hospital', Accident, Analysis and Prevention, vol. 47, pp. $11-5$.

Meyer, U, Chuard, C \& Regamey, C 2005, ‘Occupational exposures with risk of transmission of HIV, HBC and HCV in health care workers', Revue Medicale Suisse, vol. 1, no. 36, pp. 2327-31.
Mohammad Nejad, E, Asfandband, M, Ehsani, SR \& Deljoo, R 2009, ' [Epidemiological aspects of the nurses' occupational exposure to sharp objects (Persian)]', Iranian Journal of Infectious Diseases and Tropical Medicine, vol. 14, no. 45, pp. 47-50.

Moro, PL, Moore, A, Balcacer, P, Montero, A, Diaz, D, Gómez, V et al 2007, 'Epidemiology of needle sticks and other sharps injuries and injection safety practices in the Dominican Republic', American Journal of Infection Control, vol. 35, no. 8, pp. $552-9$.

Nagao, Y, Baba, H, Torii, K, Nagao, M, Hatakeyama, K, linuma, $\mathrm{Y}$ et al 2007, 'A long-term study of sharps injuries among health care workers in Japan', American Journal of Infection Control, vol. 35, no. 6, pp. 407-11.

Nasiri, E, Mortazavi, Y, Siamian, H \& Shabankhani, B 2005, '[The prevalence and study of the rate of needlestick injuries infected by blood in staff of intensive wards of teaching and non-teaching hospitals of Mazandaran province in 2003-2004 (Persian)]', Iranian Journal of Infectious Diseases and Tropical Medicine, vol. 10, no. 29, pp. 41-46.

Park, S, Jeong, I, Huh, J, Yoon, Y, Lee, S \& Choi, C 2008, 'Needlestick and sharps injuries in a tertiary hospital in the Republic of Korea', American Journal of Infection Control, vol. 36, no. 6, pp. $439-43$.

Perry, J, Parker, G \& Jagger, J 2005, 'Percutaneous Injury Rates', Advances in Exposure Prevention, vol. 7, no. 4, pp. 42-45.

Sepkowitz, KL 2000, 'Nosocomial hepatitis and other infection transmitted by blood and blood product', in GL Mandell, JE Bennett, $\mathrm{R}$ Dolin (eds), Textbook of principle and practice of infection diseases, $5^{\text {th }}$ edn, Churchill Livingstone, Philadelphia.

Siddique, KH, Mirza, S, Tauqir, SF, Anwar, I \& Malik, AZ 2008 , 'Knowledge attitude and practices regarding Needle stick injuries amongst health care providers', Journal of Surgery Pakistan, vol. 24, no. 4, pp. 243-8.

Smith, DR, Mihashi, M, Adachi, Y, Nakashima, Y \& Ishitake, T 2006a, 'Epidemiology of needle-stick and sharps injuries among nurses in a Japanese teaching hospital', Journal of Hospital Infection, vol. 64, no. 1, pp. 44-9.

Smith, DR, Smyth, W, Leggat, PA \& Wang, RS 2006b, 'Needlestick and sharps injuries among nurses in a tropical Australian hospital', International Journal of Nursing Practice, vol. 12, no. 2, pp. 71-7.

Trim, JC \& Elliott, TS 2003, 'A review of Sharps Injuries and Preventative Strategies', Journal of Hospital Infection, vol. 53, no. 4, pp. 237-42.

Vahedi, MS, Ahsan, B, Ardalan, M \& Shahsavari, S 2006, ' [Prevalence and causes of needle stick injuries, in Medical personnel of Kurdistan University Hospitals and dealing with such injuries due to contaminated sharp tools in 2004 (Persian)]'. Scientific Journal of Kurdistan University of Medical Sciences, vol. 11, no. 2, pp. 43-50 